\title{
International variation in dialysis discontinuation in patients with advanced kidney disease
}

\author{
Sarbjit V. Jassal MD PhD, Maria Larkina MS, Kitty J. Jager MD, Fliss E.M. Murtagh MD PhD, \\ Ann M. O’Hare MD MA, Norio Hanafusa MD PhD, Hal Morgenstern PhD, Friedrich K. Port MD MS, \\ Keith McCullough PhD, Ronald Pisoni MD, Francesca Tentori MD MS, Rachel Perlman MD, Richard D. Swartz MD
}

Cite as: CMAJ 2020 August 31;192:E995-1002. doi: 10.1503/cmaj.191631

\begin{abstract}
BACKGROUND: Decisions about dialysis for advanced kidney disease are often strongly shaped by sociocultural and system-level factors rather than the priorities and values of individual patients. We examined international variation in the uptake of conservative approaches to the care of patients with advanced kidney disease, in particular discontinuation of dialysis.
\end{abstract}

METHODS: We employed an observational cohort study design using data collected from patients maintained on long-term hemodialysis between 1996 and 2015 in facilities across 12 developed countries participating in the Dialysis Outcomes and Practice Patterns Study (DOPPS). The main outcome was discontinuation of dialysis therapy. We analyzed the association between several patient characteristics and time to dialysis discontinuation by country and phase of study entry.

RESULTS: A total of 259343 DOPPS patients contributed data to the study, of whom 48519 (18.7\%) died during the study period. Of the decedents, 5808 (12.0\%) discontinued dialysis before death. Rates of discontinuation were higher within the first few months after initiation of dialysis, among older adults, among those with a greater number of comorbidities and among those living in an institution. After adjustment for age, sex, dialysis duration, diabetes and dialysis era, rates of discontinuation were highest in Canada, the United
States and Australia/New Zealand (33.8, 31.4 and 21.5 per $1000 / y r$, respectively) and lowest in Japan and Italy $(<0.1$ per $1000 / y r)$. Crude discontinuation rates were highest in dialysis facilities that were more likely to offer comprehensive conservative renal care to older adults.

INTERPRETATION: We found persistent international variation in average rates of dialysis discontinuation not explained by differences in patient case-mix. These differences may reflect physician-, facilityand society-level differences in clinical practice. There may be opportunities for international cross-collaboration to improve support for patients with endstage renal disease who prefer a more conservative approach.

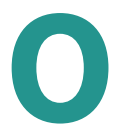
ver the last 50 years, there has been a marked increase in the availability of dialysis therapy for the treatment of both acute and chronic kidney disease, as well as shifts in the characteristics of patients treated with dialysis. Although dialysis treatment has extended life for many patients, the widespread availability of this therapy regardless of age and health status also raises questions about the role of technology in extending life and prolonging the dying process. Questions about whether and when to initiate and discontinue dialysis treatment, and the appropriateness of care, can often be extremely challenging for individual patients, families and providers. ${ }^{1}$
Evidence from the United States and elsewhere suggests that decisions about dialysis are often strongly shaped by sociocultural and system-level factors rather than the priorities and values of individual patients. ${ }^{2-4}$ Although dialysis may extend life, it is not a cure for patients' underlying kidney disease but, rather, a supportive or palliative intervention. Dialysis can treat the signs and symptoms of advanced kidney disease, support patients with acute kidney injury until their renal function recovers, and provide a bridge to transplantation. ${ }^{5}$ Reports from several developed countries indicate that a substantial portion of patients with end-stage renal disease ultimately discontinue maintenance dialysis treatments, with as many as 
$10 \%-20 \%$ of deaths of patients maintained on dialysis occurring after a decision is made to stop dialysis therapy. ${ }^{6-12}$

Rates of dialysis discontinuation vary across countries. The highest have been reported from the US, Canada, Australia and New Zealand, and the United Kingdom, and the lowest from southern Europe and Japan. ${ }^{6,8,9,13,14}$ Geographic differences in discontinuation rates likely reflect differences across countries in patient case-mix, physician attitudes ${ }^{15-17}$ and rates of commencing dialysis, but may also reflect variability in the definition of dialysis discontinuation or people's interpretation of what it means to discontinue dialysis. Initiation of dialysis in frail, older people has become more common in recent years, despite mounting evidence that this may not restore health or prolong life, particularly in those with multiple comorbidities. ${ }^{18}$

We interrogated data from a large international cohort study of patients undergoing dialysis to describe dialysis discontinuation rates by country and over time, and identify patient and facility factors associated with discontinuation of dialysis.

\section{Methods}

\section{Data sources and variables}

All data were derived from data collection instruments used in the Dialysis Outcomes and Practice Patterns Study (DOPPS) (www.dopps.org), an ongoing study of more than 250000 patients undergoing dialysis treatment across 12 countries that has evolved over 5 funding phases from 1996 to 2015 (phases 1 [1996-2001], 2 [2002-2004], 3 [2006-2008], 4 [20092011] and 5 [2012-2015]). Dialysis facilities and DOPPS sample study participants were selected by means of a stratified random

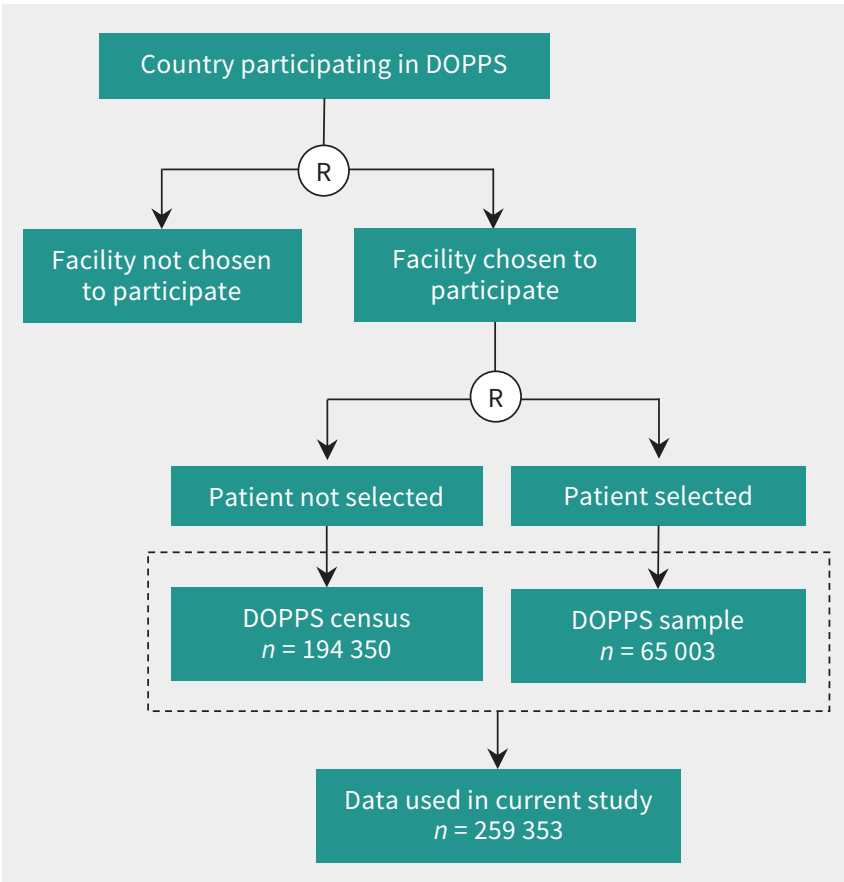

Figure 1: Process chart showing Dialysis Outcomes and Practice Patterns Study (DOPPS) study design and data sources. Dotted box represents data used to determine dialysis discontinuation information. Note: $\mathrm{R}=$ randomization . sampling process. ${ }^{19}$ All participating facilities submitted a list of all patients (DOPPS census), from which detailed information was gathered about individual patients selected at random (DOPPS sample) (Figure 1). Facilities with fewer than 20 patients were excluded. All patients who received hemodialysis at participating facilities from 1996 to 2015 in Australia/New Zealand, Belgium, Canada, France, Germany, Italy, Japan, Spain, Sweden, the UK and the US were captured in a census report. Patients were followed until censoring at the end of study follow-up (June 30, 2015), or at the time each study patient left the facility because of dialysis discontinuation (described below), transplantation, transfer to another facility or death. In addition to census data, detailed data are collected prospectively from patients selected randomly. This process is designed to ensure representation across different practice units in each country. We used data from 3 different components of the DOPPS data set (Figure 1 and Appendix 1, available at www.cmaj.ca/lookup/suppl/doi:10. 1503/cmaj.191631/-/DC1).

The primary outcome was discontinuation of dialysis during the study period. Dialysis discontinuation was determined from data entered by facility personnel who collected information on the reason why patients left the facility. Mutually exclusive options listed on the data collection documents for leaving the facility were death, dialysis discontinuation, transplantation, transfer to another facility and regaining of kidney function. Date of death was obtained for any patient who died while undergoing care at or within 30 days of leaving the facility. Discontinuation data were unavailable for 1 large organization in the US during phases 4 and 5. Dialysis discontinuation rates across different countries and periods were described with the use of DOPPS census data (a listing of all patients undergoing hemodialysis being treated in every eligible DOPPS facility).

We ascertained patient characteristics, including clinical factors, associated with dialysis discontinuation from data in the DOPPS sample ( $n=65003$ ) (www.dopps.org). We determined health care professional attitudes and practices from the DOPPS medical director survey (577 responses received of 686 survey requests [ $84 \%$ response rate]). We calculated age at dialysis initiation from the age at the time of study entry and the length of time the patient had been maintained on longterm dialysis therapy before recruitment.

\section{Statistical analysis}

We used DOPPS census data to estimate rates of dialysis discontinuation across the different participating DOPPS countries by phase, adjusted for age at time of dialysis initiation, duration of dialysis at the start of DOPPS, gender and diabetic status. We used standard descriptive statistics to characterize DOPPS participants and to compare the characteristics of the DOPPS sample to those of all prevalent patients receiving care in participating facilities (DOPPS census).

With regard to factors associated with dialysis discontinuation, time at risk started at study enrolment and ended at the time of death (including patients who discontinued dialysis), 7 days after leaving the facility because of transplantation or transfer, 7 days after changing modality or loss to follow-up. We 
used Cox regression to analyze the association between patient characteristics (age at dialysis initiation, gender, diabetes, duration of dialysis at study entry) and time to discontinuation, stratified by country and phase, accounting for facility clustering using robust sandwich covariance estimators. We used a time-dependent model adjusted for case-mix to evaluate discontinuation within the first 4 months after dialysis initiation versus discontinuation later, whereby each patient could contribute time to each category based on when he or she entered the study. We calculated standardized rates by weighting the withdrawal event and time at risk for each patient according to the overall distribution of age ( $<80 \mathrm{yr} v . \geq 80 \mathrm{yr}$ ) and duration of dialysis ( $<6 \mathrm{mov}$. $\geq 6 \mathrm{mo}$ ), as these 2 variables were the 2 casemix factors that seemed to have the strongest association with dialysis discontinuation.

\section{Ethics approval}

The DOPPS has ethics approval from a central institutional review board, with additional study approval and patient consent being obtained as required by national and local ethics committee regulations.

\section{Results}

A total of 259343 patients were included (Figure 1). Of these, 48519 (18.7\%) died during study follow-up. Dialysis discontinuation was listed as the reason for leaving the facility for 5808 patients who died (12.0\%), 256 (4.4\%) of whom died more than 30 days after dialysis discontinuation. The median time from dialysis discontinuation to death was 7 days (interquartile range 5 to $9 \mathrm{~d}$ ).

Compared to decedents who did not discontinue dialysis, those who discontinued dialysis were on average older and more likely to be female (Table 1). Age was strongly associated with

Table 1: Characteristics of census patients (all patients in participating facilities) from census population of the Dialysis Outcomes and Practice Patterns Study, phases 1-5*

\begin{tabular}{|c|c|c|c|}
\hline Characteristic & $\begin{array}{l}\text { Discontinued } \\
\text { dialysis } \\
n=5808\end{array}$ & $\begin{array}{l}\text { Died (other } \\
\text { causes) } \\
n=42711\end{array}$ & $\begin{array}{l}\text { Alive at study } \\
\text { end } \\
n=207068\end{array}$ \\
\hline Age, mean $\pm S D, y r$ & $73 \pm 12$ & $69 \pm 13$ & $61 \pm 15$ \\
\hline $\begin{array}{l}\text { Dialysis duration at } \\
\text { study start, mean } \\
\pm \mathrm{SD}, \mathrm{yr}\end{array}$ & $2.5 \pm 3.6$ & $3.6 \pm 5.0$ & $3.6 \pm 5.5$ \\
\hline $\begin{array}{l}\text { Male gender, } \\
\text { no. }(\%)\end{array}$ & $3085(53.1)$ & $24989(58.5)$ & $123705(59.7)$ \\
\hline Diabetic, no. (\%) & $2468(42.5)$ & $18227(42.7)$ & $74498(36.0)$ \\
\hline $\begin{array}{l}\text { Study follow-up } \\
\text { time, median } \\
\text { (range), yr }\end{array}$ & $0.7(0.3$ to 1.4$)$ & $0.8(0.3$ to 1.5$)$ & $1.3(0.4$ to 2.3$)$ \\
\hline \multicolumn{4}{|c|}{$\begin{array}{l}\text { Note: } \mathrm{SD}=\text { standard deviation. } \\
\text { *Data from Russia, China, Turkey and Gulf Cooperation Council countries were } \\
\text { excluded, as were phase } 5 \text { data from } 1 \text { large US dialysis organization, as dialysis } \\
\text { discontinuation information was not reported. }\end{array}$} \\
\hline
\end{tabular}

discontinuation, with a 1.9 -fold (95\% confidence interval $[\mathrm{Cl}] 1.8$ to 2.1) higher hazard ratio for discontinuation seen for patients aged $70-79$ years compared to those aged $60-69$, a 3-fold $(95 \% \mathrm{Cl}$ 3.0 to 3.7) higher hazard ratio for those aged $80-89$ years, and a 5.8 -fold $(95 \% \mathrm{Cl} 4.5$ to 7.4 ) higher hazard ratio for those aged 90 years or more.

The characteristics of participants who discontinued dialysis were similar in the DOPPS sample and the DOPPS census (Appendix 1, Supplemental Table S1). Among patients included in the DOPPS sample ( $n=65003$ ), those who discontinued dialysis were more likely to require assistance with eating or transfers or both, be living in an institution and have a higher number of comorbid conditions at study entry than those who died of other causes (Table 2). Of the 1077 patients with detailed information about the reasons for discontinuation, 388 (36.0\%) discontinued dialysis following an acute medical condition, and 291 (27.0\%) following chronic progressive deterioration in health. A total of 840 patients $(78.0 \%)$ discontinued dialysis at the patient's or family's request. Most (743 [69.0\%]) of those who stopped dialysis received hospice or palliative care before death.

In all DOPPS phases, there was marked international variation in rates of dialysis discontinuation, with no apparent change over time (Appendix 1, Supplemental Figure S1). In all phases, dialysis discontinuation was most common in Canada (33/1000 patient-years), the US (27/1000 patient-years) and Australia/New Zealand (21/1000 patient-years); discontinuation was least common in Spain (5/1000 patient-years), Japan (0/1000 patient-years) and Italy (0/1000 patient-years) (Table 3$)$. These differences persisted even after adjustment for differences in the baseline characteristics of patients undergoing dialysis (Figure 2). Patients living in countries with higher rates of discontinuation such as the US, Canada, Australia/New Zealand and Belgium were also more likely to discontinue dialysis within 4 months of starting treatment than after 4 months of treatment (Figure 3). The hazard ratios (adjusted for age at dialysis initiation, gender and diabetes) for discontinuation within 4 months versus after 4 months of starting treatment in the US, Canada, Australia/New Zealand and Belgium ranged from 1.5 for the US and Belgium to 2.0 for Canada $(p<0.05)$. The median age, diabetes status and median duration of dialysis at the time of dialysis discontinuation differed little across countries with high or low discontinuation rates (Appendix 1, Supplemental Table S2, Supplemental Figures S2 and S3).

We found substantial differences across countries in responses to the medical director survey. Medical directors of most units (15/16 [94\%]) in Australia/New Zealand reported that they always or usually discussed comprehensive conservative renal care. In contrast, medical directors of 103/105 units $(98 \%)$ in Japan reported that they never or seldom discussed comprehensive conservative renal care. We found a positive linear association between the frequency of discussing comprehensive conservative renal care with older patients and facility discontinuation of dialysis rates (Figure 4). When modelled as a linear trend in the facility-level discontinuations per 1000 patient-years, the association between discussing 
Table 2: Characteristics of patients selected for participation in the Dialysis Outcomes and Practice Patterns Study, phases 1-5 (sample, $n=65003$ )

\begin{tabular}{|c|c|c|c|}
\hline Characteristic & $\begin{array}{c}\text { Discontinued } \\
\text { dialysis } \\
n=1525\end{array}$ & $\begin{array}{c}\text { Died (other } \\
\text { causes) } \\
n=12720\end{array}$ & $\begin{array}{l}\text { Alive at study end } \\
\qquad n=50755\end{array}$ \\
\hline Age, mean $\pm S D, y r$ & $72.8 \pm 11.8$ & $69.3 \pm 12.5$ & $61.1 \pm 14.9$ \\
\hline Dialysis duration, mean $\pm \mathrm{SD}$, yr & $2.6 \pm 3.7$ & $3.6 \pm 4.8$ & $3.8 \pm 5.6$ \\
\hline Body mass index, mean \pm SD & $24.9 \pm 5.7$ & $24 \cdot 7 \pm 5.8$ & $25.2 \pm 5.9$ \\
\hline Male gender, no. (\%) & $815(53.4)$ & $7515(59.1)$ & $30098(59.3)$ \\
\hline \multicolumn{4}{|l|}{ Laboratory values } \\
\hline Albumin level, mean $\pm S D, g / d L$ & $3.5 \pm 0.6$ & $3.5 \pm 0.6$ & $3.7 \pm 0.5$ \\
\hline $\begin{array}{l}\text { Creatinine level, mean } \pm S D \text {, } \\
\mu \mathrm{mol} / \mathrm{L}\end{array}$ & $602 \pm 220$ & $664 \pm 238$ & $778 \pm 283$ \\
\hline \multicolumn{4}{|l|}{ Comorbidity information, no. (\%) } \\
\hline Coronary heart disease & $926(60.7)$ & $7154(56.2)$ & $18789(37.0)$ \\
\hline Other cardiovascular disease & $726(47.6)$ & $5752(45.2)$ & $14174(27.9)$ \\
\hline Cerebrovascular disease & $418(27.4)$ & $3017(23.7)$ & $7014(13.8)$ \\
\hline Congestive heart failure & $742(48.7)$ & $5747(45.2)$ & $13115(25.8)$ \\
\hline Diabetes & $745(48.8)$ & $6074(47.8)$ & $18933(37.3)$ \\
\hline Gastrointestinal bleeding & $145(9.5)$ & $1130(8.9)$ & $2417(4.8)$ \\
\hline HIV infection & $8(0.5)$ & $91(0.7)$ & $286(0.6)$ \\
\hline Hypertension & $1258(82.5)$ & $10357(81.4)$ & $40940(80.7)$ \\
\hline Lung disease & $357(23.4)$ & $2515(19.8)$ & $4757(9.4)$ \\
\hline Neurologic disease & $308(20.2)$ & 2025 (15.9) & $4334(8.5)$ \\
\hline Psychiatric disorder & $424(27.8)$ & $2901(22.8)$ & 8090 (15.9) \\
\hline Peripheral vascular disease & $615(40.3)$ & $5056(39.7)$ & $10918(21.5)$ \\
\hline Recurrent cellulitis/gangrene & $205(13.4)$ & $1817(14.3)$ & $3145(6.2)$ \\
\hline Cancer other than skin & $358(23.5)$ & $2196(17.3)$ & $5673(11.2)$ \\
\hline Cachexia & $264(17.3)$ & $1775(14.0)$ & $3076(6.1)$ \\
\hline \multicolumn{4}{|l|}{ Living status, no. $(\%)^{\star}$} \\
\hline Lives alone & $284(18.6)$ & $2134(16.8)$ & $8437(16.6)$ \\
\hline Lives with family or friend & $948(62.2)$ & $8892(69.9)$ & $38590(76.0)$ \\
\hline Lives in nursing home or institution & $249(16.3)$ & $1210(9.5)$ & $1640(3.2)$ \\
\hline \multicolumn{4}{|l|}{ Functional status, no. (\%) } \\
\hline Eats independently & $1398(91.7)$ & $11799(92.8)$ & $49072(96.7)$ \\
\hline Able to transfer independently & $1003(65.8)$ & $8395(66.0)$ & $40402(79.6)$ \\
\hline
\end{tabular}

comprehensive conservative renal care and the observed discontinuation rate was $6.1(95 \% \mathrm{Cl} 4.1$ to 8.1$)$ per singlecategory increase in the comprehensive conservative renal care response (e.g., from "seldom" to "half the time"), but when adjusted for country, this trend decreased to $0.8(95 \% \mathrm{Cl}-1.5$ to 3.2). There was greater consistency in medical director responses among facilities within than between countries, which meant that the relation became much weaker when adjusted for country. Dialysis discontinuation rates were also higher in units where the medical director reported that the facility's practice was to usually or always recommend discontinuation after an event causing irreversible neurologic damage, but the observation was rendered not statistically significant with adjustment for country.

Overall, 87 facilities (16\%) (at least 1 in every country) responded that physicians in their area would never or seldom refer patients older than 80 years to dialysis, and these responses were associated with significantly lower facility discontinuation rates after adjustment for country and age. Medical director responses to the question about dialysis 
Table 3: Crude and standardized dialysis discontinuation rates per 1000 patient-years across countries participating in the Dialysis Outcomes and Practice Patterns Study, phases 4 and 5

\begin{tabular}{|c|c|c|}
\hline \multirow[b]{2}{*}{ Country } & \multicolumn{2}{|c|}{ Median rate per 1000 patient-years } \\
\hline & Unadjusted & Standardized* \\
\hline Overall & 5.3 & 4.8 \\
\hline United States & 26.7 & 31.4 \\
\hline Canada & 33.3 & 33.8 \\
\hline Australia and New Zealand & 21.4 & 21.5 \\
\hline United Kingdom & 12.2 & 10.9 \\
\hline Sweden & 13.3 & 15.6 \\
\hline Belgium & 8.3 & 7.1 \\
\hline France & 0.0 & 0.9 \\
\hline Germany & 3.1 & 3.3 \\
\hline Italy & 0.0 & 0.0 \\
\hline Spain & 4.8 & 3.6 \\
\hline Japan & 0.0 & 0.0 \\
\hline \multicolumn{3}{|c|}{$\begin{array}{l}\text { *The standardized rate used as a reference in the overall Dialysis Outcomes and } \\
\text { Practice Patterns Study distribution during phases } 4 \text { and } 5 \text { in terms of age }(<80 \mathrm{yr} \text { v. } \\
\geq 80 \mathrm{yr} \text { ) and duration of dialysis }(<6 \mathrm{mo} \text { v. } \geq 6 \mathrm{mo}) \text {. Standardized rates excluded } \\
\text { patients with missing duration of dialysis }(1.7 \%) \text { or missing age }(0.3 \%) \text {, which left } \\
86641 \text { patients. The median difference in unadjusted and standardized facility dialysis } \\
\text { discontinuation rates was } 0.0 \text { (interquartile range } 0.0 \text { to } 1.1 \text { ) per } 1000 \text { patient-years. }\end{array}$} \\
\hline
\end{tabular}

discontinuation practices for patients with metastatic cancer and a life expectancy of less than 6 months were not associated with discontinuation rates in either unadjusted or adjusted analyses.

\section{Interpretation}

We found substantial international variation in dialysis discontinuation rates, despite accumulating evidence of the limited benefits of dialysis for frail older adults. ${ }^{18}$ Dialysis remains one of the most expensive and invasive treatments available. Although some countries struggle to find the resources to provide access to dialysis for patients with renal failure, in much of the developed world, dialysis initiation has become the default treatment for advanced kidney disease, which has raised concerns about overtreatment. ${ }^{3,4}$ We found that international variations in dialysis discontinuation practices are not well explained by patient case-mix alone; rather, unit and physician practices influence discontinuation rates. This finding raises questions as to the main drivers, outside of patient values and preferences, that influence dialysis treatment decisions. ${ }^{3}$

In a survey of medical directors at participating facilities, there was considerable variation in responses to several questions related to dialysis discontinuation, with a strong association between responses and rates of dialysis discontinuation

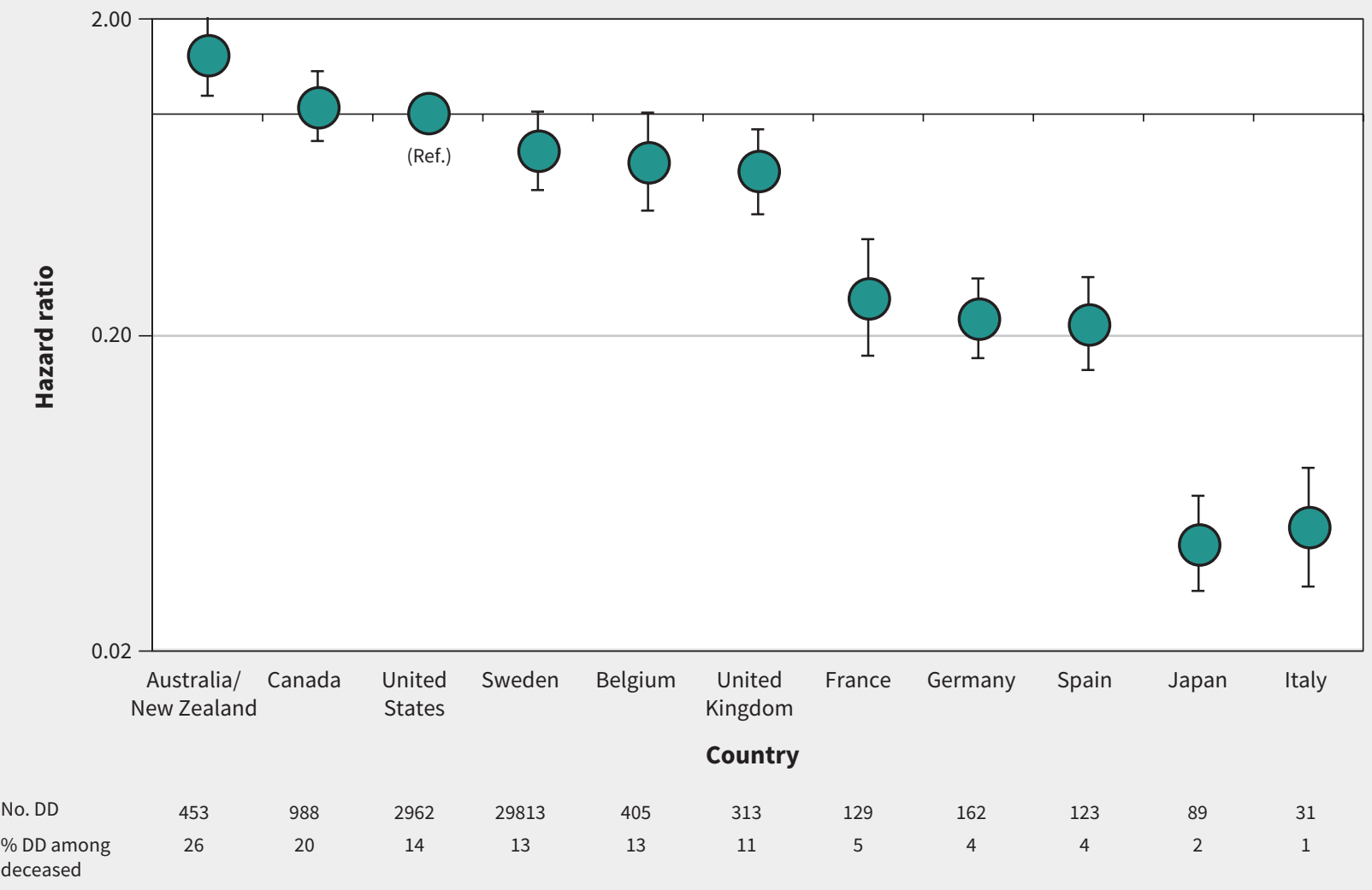

Figure 2: Adjusted dialysis discontinuation (DD) rate by country (hazard log scale) in phases 1-5 of the Dialysis Outcomes and Practice Patterns Study, excluding 1 large US dialysis organization in phases 4 and 5. Cox model adjusted for country, age, duration of dialysis, gender and diabetes, censoring any death events. Note: Ref. = reference. Error bars represent $95 \%$ confidence intervals. 


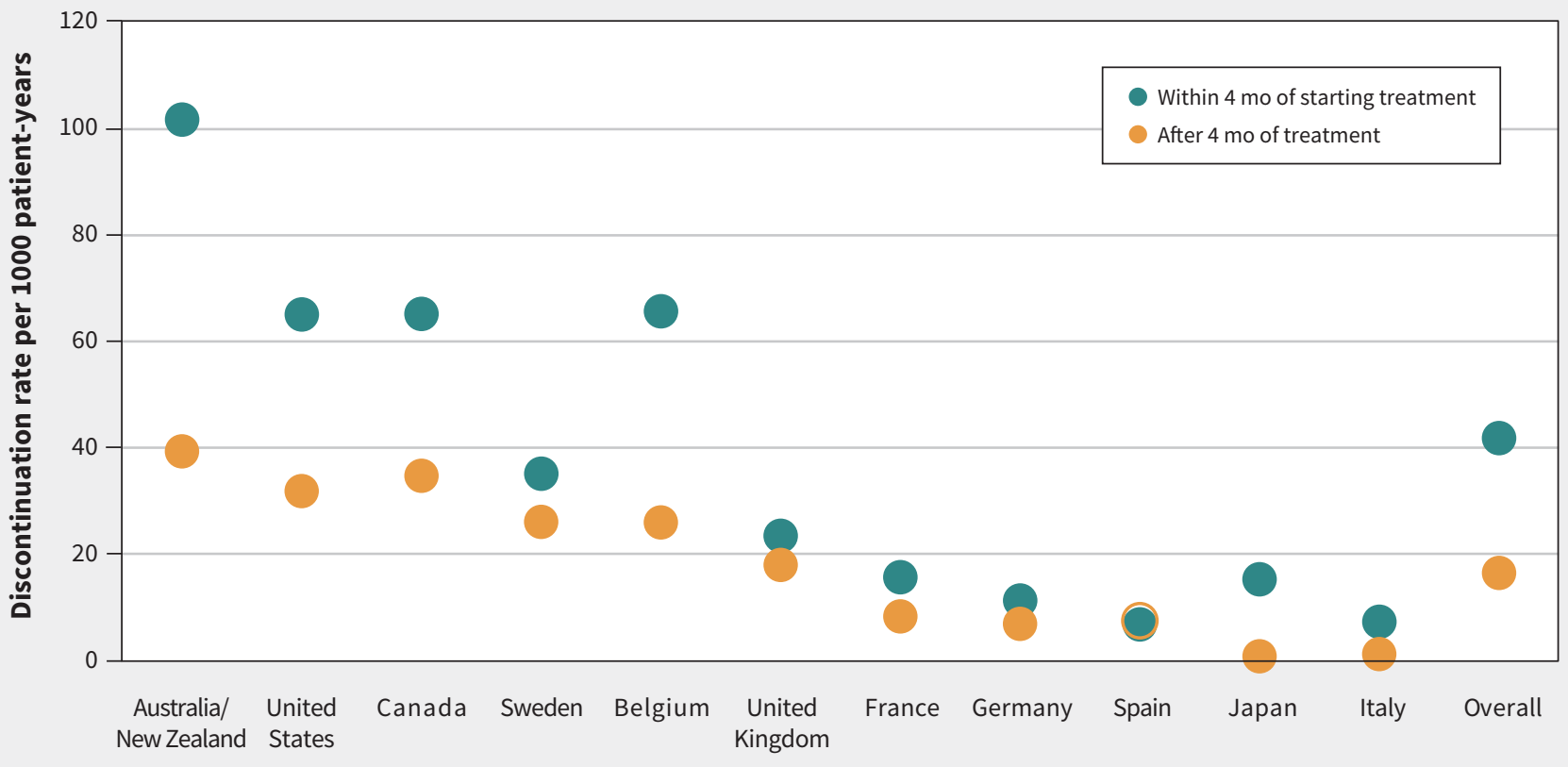

Country

Figure 3: Unadjusted discontinuation rate (raw data unmodelled) by country during the first 4 months after dialysis initiation and during subsequent follow-up in phases 1-5 of the Dialysis Outcomes and Practice Patterns Study, excluding 1 large US dialysis organization in phases 4 and 5. Each patient could contribute time to both categories.
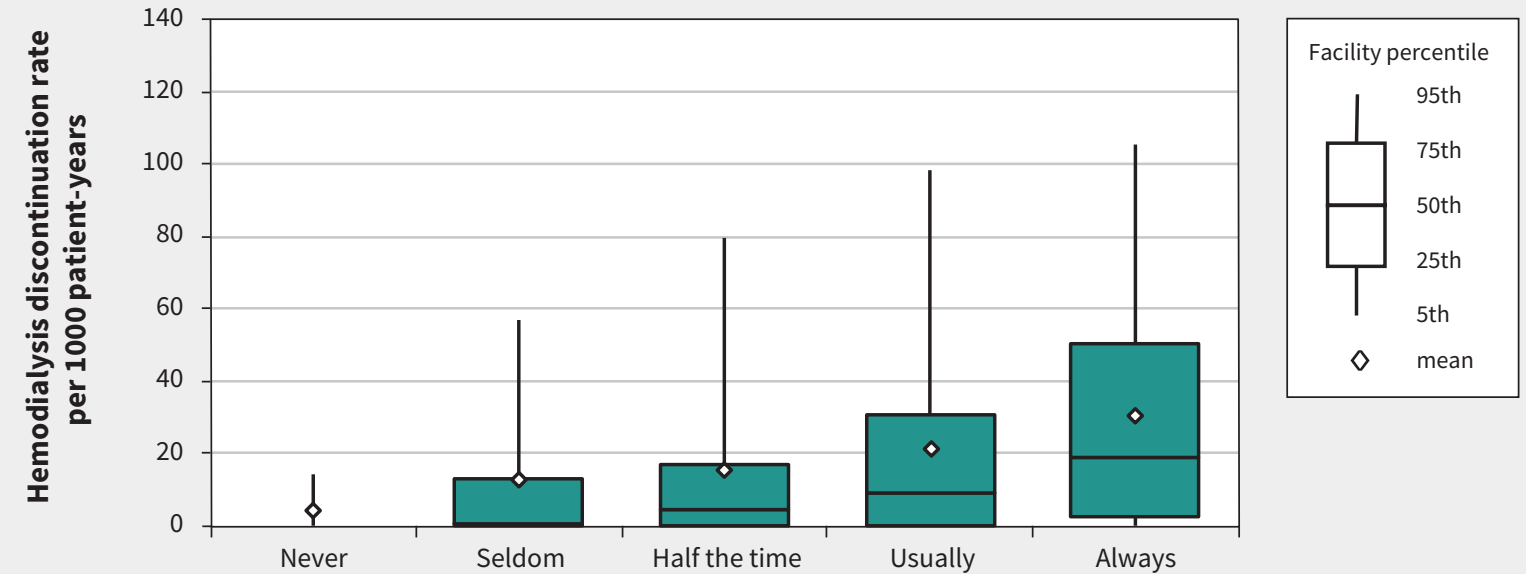

Director willingness to initiate conservative care

$\begin{array}{lllccl}\text { No. of facilities } & 61 & 170 & 60 & 93 & 128 \\ \text { No. of patients } & 52 & 438 & 153 & 344 & 677\end{array}$

Figure 4: Facility hemodialysis discontinuation rate according to the medical director's self-reported willingness to offer comprehensive conservative renal care instead of dialysis initiation for elderly patients approaching end-stage renal disease (unadjusted). Data from phases 4 and 5 medical director survey aligned with facilities' corresponding discontinuation rate among all patients undergoing hemodialysis who received care during the study phase, excluding 1 large US dialysis organization in phases 4 and 5. 
at each facility, which is consistent with other studies suggesting that dialysis treatment patterns are largely shaped by provider- and system-level factors rather than the preferences of individual patients. ${ }^{17,20-23}$ In the present study, patients were more likely to discontinue dialysis early in the course of treatment, ${ }^{13}$ and high rates of discontinuation were often associated with high rates of early discontinuation, which may reflect a more liberal approach to dialysis initiation or greater use of time-limited trials of therapy with the option of planned discontinuation.

\section{Limitations}

Limitations of our study relate largely to limitations in the available data. Only patients who started dialysis were included in the study; rates of comprehensive conservative renal care differ among countries, ${ }^{24}$ and patients who opt for such care instead of dialysis may differ from those who decide to discontinue dialysis after starting it. In addition, factors such as transplantation wait times, distance to travel to dialysis, and availability and quality of palliative care services can influence the patient's experience and affect discontinuation rates. Importantly, interpretation of "discontinuation" may vary. Previous work suggests that the term is used differently across countries and regions, and between nephrologists within the same units, ${ }^{12,16,25-27}$ and our results may reflect how people completing the data collection forms have incorporated their personal or local cultural values into the interpretation.

\section{Conclusion}

We found regional differences in dialysis discontinuation among patients with end stage renal disease in our large international sample. These findings raise questions about how regional differences in physician experience and training, societal expectations and medicolegal regulations affect patient care, particularly for those who may not feel well served by long-term dialysis. ${ }^{20,22,28}$ Furthermore, they suggest an ongoing need to increase training in provision of care for all patients on the kidney disease spectrum, including those who require endof-life care, and possibly align clinical practices to better meet patients' needs.

\section{References}

1. Russ AJ, Shim JK, Kaufman SR. The value of "life at any cost": talk about stopping kidney dialysis. Soc Sci Med 2007;64:2236-47.

2. Thorsteinsdottir B, Swetz KM, Albright RC. The ethics of chronic dialysis for the older patient: time to reevaluate the norms. Clin J Am Soc Nephrol 2015;10: 2094-9.

3. Elshaug AG, Rosenthal MB, Lavis JN, et al. Levers for addressing medical underuse and overuse: achieving high-value health care. Lancet 2017;390: 191-202.

4. Brownlee S, Chalkidou K, Doust J, et al. Evidence for overuse of medical services around the world. Lancet 2017;390:156-68.

5. Churchill DN, Jassal SV. Dialysis: destination or journey. J Am Soc Nephrol 2014; 25:1609-11.

6. Leggat JE Jr, Bloembergen WE, Levine G, et al. An analysis of risk factors for withdrawal from dialysis before death. J Am Soc Nephrol 1997;8:1755-63.
7. Bordenave K, Tzamaloukas AH, Conneen S, et al. Twenty-one year mortality in a dialysis unit: changing effect of withdrawal from dialysis. ASAIO J 1998;44: 194-8.

8. Chan HW, Clayton PA, McDonald SP, et al. Risk factors for dialysis withdrawal: an analysis of the Australia and New Zealand Dialysis and Transplant (ANZDATA) Registry, 1999-2008. Clin J Am Soc Nephrol 2012;7:775-81.

9. Ellwood $A D$, Jassal SV, Suri RS, et al. Early dialysis initiation and rates and timing of withdrawal from dialysis in Canada. Clin J Am Soc Nephrol 2013;8:265-70.

10. Aggarwal Y, Baharani J. End-of-life decision making: withdrawing from dialysis: a 12-year retrospective single centre experience from the UK. BMJ Support Palliat Care 2014;4:368-76.

11. Birmelé B, François M, Pengloan J, et al. Death after withdrawal from dialysis: the most common cause of death in a French dialysis population. Nephrol Dial Transplant 2004;19:686-91.

12. Findlay MD, Donaldson K, Doyle A, et al.; Scottish Renal Registry (SRR). Factors influencing withdrawal from dialysis: a national registry study. Nephrol Dial Transplant 2016;31:2041-8.

13. Fissell RB, Bragg-Gresham JL, Lopes AA, et al. Factors associated with "Do Not Resuscitate" orders and rates of withdrawal from hemodialysis in the international DOPPS. Kidney Int 2005;68:1282-8.

14. Lambie M, Rayner HC, Bragg-Gresham JL, et al. Starting and withdrawing haemodialysis - associations between nephrologists' opinions, patient characteristics and practice patterns (data from the Dialysis Outcomes and Practice Patterns Study). Nephrol Dial Transplant 2006;21:2814-20.

15. Sekkarie MA, Moss AH. Withholding and withdrawing dialysis: the role of physician specialty and education and patient functional status. Am J Kidney Dis 1998;31:464-72.

16. Kee F, Patterson CC, Wilson EA, et al. Stewardship or clinical freedom? Variations in dialysis decision making. Nephrol Dial Transplant 2000;15:1647-57.

17. Fung E, Slesnick N, Kurella Tamura M, et al. A survey of views and practice patterns of dialysis medical directors toward end-of-life decision making for patients with end-stage renal disease. Palliat Med 2016;30:653-60.

18. Foote C, Kotwal S, Gallagher M, et al. Survival outcomes of supportive care versus dialysis therapies for elderly patients with end-stage kidney disease: a systematic review and meta-analysis. Nephrology (Carlton) 2016; 21:241-53.

19. Pisoni RL, Gillespie BW, Dickinson DM, et al. The Dialysis Outcomes and Practice Patterns Study (DOPPS): design, data elements, and methodology. Am J Kidney Dis 2004;44(Suppl 2):7-15.

20. Grubbs V, Tuot DS, Powe NR, et al. System-level barriers and facilitators for foregoing or withdrawing dialysis: a qualitative study of nephrologists in the United States and England. Am J Kidney Dis 2017;70:602-10.

21. Lovell S, Walker RJ, Schollum JB, et al. To dialyse or delay: a qualitative study of older New Zealanders' perceptions and experiences of decision-making, with stage 5 chronic kidney disease. BMJ Open 2017;7:e014781.

22. van Biesen W, van de Luijtgaarden MW, Brown EA, et al. Nephrologists' perceptions regarding dialysis withdrawal and palliative care in Europe: lessons from a European Renal Best Practice survey. Nephrol Dial Transplant 2015;30: 1951-8.

23. Ladin K, Pandya R, Kannam A, et al. Discussing conservative management with older patients with CKD: an interview study of nephrologists. Am J Kidney Dis 2018;71:627-35.

24. Murphy E, Germain MJ, Cairns H, et al. International variation in classification of dialysis withdrawal: a systematic review. Nephrol Dial Transplant 2014;29: 625-35.

25. van Loon IN, Boereboom FT, Bots ML, et al. A national survey on the decisionmaking process of dialysis initiation in elderly patients. Neth J Med 2015;73: 227-35.

26. Clement $\mathrm{R}$, Chevalet $\mathrm{P}$, Rodat $\mathrm{O}$, et al. Withholding or withdrawing dialysis in the elderly: the perspective of a western region of France. Nephrol Dial Transplant 2005;20:2446-52.

27. Moss AH, Stocking CB, Sachs GA, et al. Variation in the attitudes of dialysis unit medical directors toward decisions to withhold and withdraw dialysis. J Am Soc Nephrol 1993;4:229-34.

28. Pommer W, Wagner S, Thumfart J. Conservative care, dialysis withdrawal, and palliative care: results from a survey of a non-profit dialysis provider in Germany. Kidney Blood Press Res 2019;44:158-69. 
Competing interests: Kitty Jager reports speaker fees from Fresenius Medical Care. Ronald Pisoni reports that this project was supported by funds from a consortium of funders who have supported the international DOPPS Program without restrictions on publications; the organizations are listed at www. dopps.org/AboutUs/Support.aspx. No other competing interests were declared.

This article has been peer reviewed.

Affiliations: University Health Network (Jassal), Toronto, Ont.; Arbor Research Collaborative for Health (Larkina, Port, McCullough, Pisoni), Ann Arbor, Mich.; ERA-EDTA Registry (Jager), Department of Medical Informatics, Academic Medical Centre, Amsterdam Public Health Research Institute, University of Amsterdam, Amsterdam, Netherlands; Wolfson Palliative Care Research Centre (Murtagh), Hull York Medical School, University of Hull, Hull, UK; VA Puget Sound Health Care System (O'Hare), Seattle, Wash.; Department of Blood Purification (Hanafusa), Tokyo Women's Med- ical University, Tokyo, Japan; Departments of Epidemiology (Morgenstern) and Environmental Health Sciences (Morgenstern), School of Public Health, and Department of Urology (Morgenstern), Medical School, University of Michigan, Ann Arbor, Mich.; DaVita Outcomes Research and Patient Empowerment (Tentori), Denver, Colo.; Divisions of Nephrology (Perlman, Swartz) and Palliative Care (Swartz), Department of Internal Medicine, University of Michigan Health System, Ann Arbor, Mich.

Contributors: Sarbjit Jassal conceived the work. Sarbjit Jassal, Maria Larkina, Kitty Jager, Fliss Murtagh, Ann O'Hare, Norio Hanafusa, Hal Morgenstern, Friedrich Port, Francesca Tentori, Rachel Perlman, Richard Swartz and Keith McCullough designed the study. Maria Larkina and Keith McCullough analyzed the data. Sarbjit Jassal, Maria Larkina, Ann O'Hare, Hal Morgenstern, Keith McCullough, Ronald Pisoni, Francesca Tentori and Rachel Perlman interpreted the data. Sarbjit Jassal drafted the manuscript. All of the authors revised the manuscript critically for important intellectual content, gave final approval of the version to be published and agreed to be accountable for all aspects of the work.

Funding: Information about funding sources for the DOPPS project can be found at www.dopps.org/AboutUs/Support.aspx. All support is provided without restrictions on publications.

Data sharing: The Dialysis Outcomes and Practice Patterns Study (DOPPS) is committed to collaboration with qualified external researchers. Investigators wishing to develop a partnership with the DOPPS Research Group are asked to review information that can be found at https://www.dopps.org/ PartnerwithUs.aspx about how to initiate collaboration and submit a letter of intent.

Accepted: Apr. 16, 2020

Correspondence to: Sarbjit Jassal, vanita.jassal@uhn.ca 